\title{
Study and Operation on the Construction of Internal Undergraduate Governance System
}

\author{
$\mathrm{He} \mathrm{Pu}{ }^{1}$ Zhao Youbin ${ }^{2}$ Yan Haibo ${ }^{1}$ Lin Rupeng ${ }^{3}$ Zhang Hong ${ }^{1}$ \\ ${ }^{1}$ Academic Affairs Office, Jinan University, Guangzhou 510632 \\ ${ }^{2}$ School of Translation Studies, Jinan University, Zhuhai 519070 \\ ${ }^{3}$ Jinan University, Guangzhou 510632
}

\begin{abstract}
Current research on university governance mainly focuses on governing subjects but seldom exploring or constructing university internal governance systems. According to the research and practice done by the author during the undergraduate teaching, the effects of university internal governance can be achieved, by building connotation construction platforms for university internal governance at undergraduate level, promoting positive spirits of schools, teaching and learning and on that basis structuring university internal governance systems, with teachers, curriculums and students as the core components of undergraduate teaching and learning and meeting the needs of teachers and students for developments as the driving force.
\end{abstract}

Keywords: University Governance; Internal Governance System; Driving Force of Development; Undergraduate Governance System

\section{INTRODUCTION}

Against the backdrop of China's deepening reform on education, some deep-rooted issues in this area have become even more difficult to handle with. Problems involving several departments, various policies and multiple stakeholders, where existing reform measures focusing on single department or policy hardly work, are posing new challenges to the comprehensive reform on education. Turning "management" into "governance" is not only a big change in China's overall administration but also a key step to restructure the management system of the country's higher education. Existing researches on governance theory's application on undergraduate teaching and learning mainly focus on theoretical basis, connotation analysis, power description and governing subjects, highlighting de-administration and relations between government, students, parents, donators and social public. The construction of internal governance system, however, is not getting enough attention. In fact, factors influencing the operation and development of undergraduate education, which are tightly connected with one another and of different significance, form a complicated multi-level network. Therefore, the priority of building the internal undergraduate governance system is to clarify the relations between these key factors and work out a structure to correlate them with each other.

\section{Governance is the Upper Stage of Management}

"Governance theory", systematically established in 1995, belongs to the category of modern political and administrative science. According to the definition by UN Commission on Global Governance (CDD), "governance" is "the sum of many ways by which various organizations, public or private, manage their common affairs. It is a lasting process where different or even conflicting interests are coordinated and joint actions are taken". It consists of formal systems and rules people are obliged to obey, and informal institutional arrangements by common consent and in the interest of majority.

It is commonly understood that governance is the upper stage compared with management, since in this process multi-dimensional closed feedbacks are formed through formal or informal institutional arrangements and joint efforts are made by stakeholders to facilitate the development of certain object. Therefore, it can be concluded that governance differs from management in the following four aspects. First, governance lays stress on the realizing process of development and goals, while management focuses on the goal achieved by power will. The way governance achieves the goal of a certain object is to "respect stakeholders' thoughts and motivate their inner innovation" ${ }^{[1]}$. Second, governance is a multidimensional feedback process while government is a single-dimensional power-exerting process. Some believe that "governance" is "a managing process where power is exerted on multiple levels" [2]. The "structure and order" governance aims to establish "cannot be forced by external factors but depend on the interaction between many people in close relation and with ruling power" [3] Third, governance stresses on multiple subjects--all stakeholders, while management stresses on single subject--the manager. This feature can be traced back to the concept in economics that "governance is a set of institutional arrangements people use to define the relations between stakeholders to benefit all parties involved" ${ }^{[4]}$. Fourth, governance is more about "cooperative governance" and "common advancement", while management is more like the bureaucratic way emphasizing "each subject responsible for their own job". The subjects of governance do not affect the object each on their own. Rather, they "pursue the ' $1+1>2$ effect' by facilitating positive connections between subsystems in a complicated large 
system, which means they are after a result better than the simple adding-up of all individual factors" ${ }^{[5]}$.

\section{Driving Force of Internal Undergr-aduate Governance: Development of Multiple Stakeholders with Teachers and Students as Core Components}

\subsection{Teachers and Students Ought to be The Subjects of Undergraduate Governance}

University governance refers to the process stakeholders in or out of university take part in the decision-making of university affairs, with these stakeholders as subjects. Stakeholders out of university mainly include the governing party, government at all levels, employing units, students' parents, alumni, donators, partners, local community and news media; stakeholders in university mainly include senior supervisors, middle managers, teachers, students, other staff members, school groups, college (department and staff room) groups and department managing groups.

In terms of organization categories, university belongs to academic organizations. Now universities as academic organizations fail to fully exert their "academic" power, resulting in abused administrative power and weakened academic power in China's universities. In undergraduate teaching and learning, it fits the current trend to make teachers and students with "academic" features the subjects of governance and govern through correlating various environment factors.

\subsection{The Core Driving Force of Undergraduate Governance is the Development of Teachers and Students}

Between stakeholders with different interest demands, there exist not only conflicts but uniformity and mutual restriction. Teachers, "professionals who exercise the functions of education and teaching" by definition, are not only executors of "teaching" but students' "learning" guides. As is stipulated in Teachers Law of the People's Republic of China, teachers are entitled "to put forward opinions and suggestions regarding education, teaching, management of schools, and the work of the administrative departments of education". This echoes the return of "academic standard", a recent public voice in university governance, that teachers should be the soul of the all subjects in undergraduate governance instead of mere participants. Only by treating teachers as governance subjects can they concentrate on teaching and fully realize their potential. Then the academic authority in university governance may actually return. In the meanwhile, students can give feedbacks on teachers, curriculums and even the whole teaching process, instead of serving as mere subjects and products of "teaching". Marx once pointed out that "people strive for all which concern with theirs interest" ${ }^{[6]}$. Only by coordinating teacher and student authority relations and forming a highly effective mutual restrain mechanism in the interest of both parties can they be motivated to enhance schoolrunning efficiency and contribute to university development.

\subsection{Motivate Teachers and Students by Building a Governance System Focusing on Their Development}

People response to any move concerning their personal interest. What concerns teachers' interests most is apparently promotion, because it directly decides their social status and personal income, and generally describes their competence as teachers. Meanwhile, students concern most about their grades, academic degrees, ability and caliber. Factors influencing teacher's promotion are teaching and researching capacities, student's evaluation and social influence. While factors holding sway over students are talent training scheme, curriculum arrangement, teachers' competence and the spirits of "schools, learning and teaching". Now in Chinese universities, where people value scientific research over teaching, it is hard to motivate teachers and students by simply adopting the traditional mechanism of undergraduate management. The various teaching quality improving plans and promotions of positive "school, learning and teaching" spirits also fail to show any remarkable effect. The root cause is there lacks an undergraduate governance system that can balance the interests of all parties and are recognized and participated in by all stakeholders (teachers and students in particular). As a matter of fact, it can be concluded that the greatest interest of teachers and students is development, through which teachers can reap fruitful teaching and researching achievements and get promoted, and students can enjoy quality classes in a learning-friendly environment and grow into competitive talents meeting the demand of society. With "undergraduate teaching and learning" as the object, a governance system focusing on the development of teachers and students will be well accepted and actively participated by teachers and students. Hence the maximum benefit of university is ensured.

\section{Build a Closed Feedback Governance System Driven by the Development Interest of Teachers and Students}

The undergraduate governance system facilitates undergraduate connotation construction by meeting the development demands of teachers and students and building developing platforms for them. Meanwhile, the system exerts power over managing groups and individual 
managers so as to secure the maximum development interest of teachers and students.

\section{1. "Three Core Elements" in Internal Undergraduate Governance: Teachers, Curriculums and Students}

Teachers, curriculums and students are the three inseparable core elements in internal undergraduate governance. As the soul of higher education, teachers, "professionals who exercise the functions of education and teaching" ${ }^{[7]}$, are executors of "teaching" and guides of "learning"; as the foundation of higher education, curriculums act as the carrier of knowledge and the link between teachers and students; students are the subject and root of higher education. However, problems exist in these three aspects. Since most teachers lack specific development goals, guidance and development platforms, they are not motivated enough to devote themselves into undergraduate teaching; present curriculums obviously lag behind the development demands of current undergraduates; the quantity and quality of innovative talents both cannot meet the demands of economic society. To construct internal undergraduate governance system, problems in teachers, curriculums and students must be solved first. Then the goal can be achieved "to train excellent core teachers, to create high-quality curriculums, and to foster innovative talents with lasting competitiveness" $^{[8]}$.

\section{2. "Three Platforms" in the Connotation Construction of Internal Undergraduate Governance: Teachers' Directional Development Platform, Curriculum Construction and Management Platform and Innovative Talent Cultivation Platform}

The core profit drive of undergraduate governance lies in the development of teachers and students; what teachers and students care about the most is also their development Therefore, to meet the development demands of teachers and students is the priority of internal undergraduate governance system.

Now problems prevailing among university teachers are unspecific development direction and more resource access (such as achievements, expenses and projects) than scientific researches. Hence, how to meet teachers' development demand and motivate them to devote in undergraduate teaching is the first problem the system will solve. It is only when teachers' development will and working interest are fully respected and their development are guided and supported by universities that their interest in undergraduate teaching can be satisfied. To build directional development platform, teachers and groups aspiring to undergraduate teaching should be absorbed. Then they will be supported with scientific guidance and separate training in terms of classroom teaching, course construction, textbook compiling, teaching reform and research, and innovative talent cultivation. At last, they will be assessed in terms of group construction in the mode of dynamic management. With the help of this platform, teachers are entitled with priority in accessing undergraduate teaching resources, participating in undergraduate teaching activities and expressing their opinions on undergraduate teaching reforms.

Curriculums serve as the structure of talent cultivation, the main channel for students to acquire knowledge and the important carrier of teachers' knowledge accumulation and construction. The essence of curriculum construction lies in two aspects. On the one hand, teachers should be given access to curriculum resource development platform so as to stimulate their development awareness and curriculum construction enthusiasm, facilitate teaching resource management, showcase teaching achievement, and motivate them to "adopt the right teaching methods" and devote themselves in teaching research. On the other hand, higher quality talents should be fostered through high quality curriculums and the best teaching and learning effect should be achieved by the interaction between teachers and students. Undergraduate curriculum construction and management platform should be built on this idea and revolve around undergraduate curriculum system. It will assess all undergraduate curriculums of a university on a regular basis, allocate supporting resources according to curriculum constructing effects, and support the further development of different grades.

The priority of higher education is to foster talents and, therefore, the talent cultivating ability is the key criteria for evaluating the education quality of a university. Nowadays, innovation, as the internal drive for development, becomes the synonym of competitiveness. The key to equip students with core competitiveness is to foster innovative leaders as well as personnel with lasting competitiveness in all walks of life. Innovative talent cultivation platform should include two parts. First, strengthen multidimensional innovative elements in course construction. Second, carry out multi-innovative talent fostering projects to systematically enhance students' innovative and enterprise ability. It is worth noting that all students should be involved instead of only a few.

\section{3. "Three Weapons" to Promote Positive "School, Teaching and Learning" Spirits in University: Graded Teaching and Learning Spirits Forewarning and Disposal System, Teaching Performance Assessing System and Class Teaching Supporting System}

Positive "school, teaching and learning" spirits, the essence of university, is of absolute importance to university development. However, promotion of the spirits has not been effective due to the absence of proper methods. Therefore, it is particularly important to form a comprehensive system highlighting the graded forewarning and disposal mechanism of teaching and learning to meet the demands of the key stakeholders in 
undergraduate education-teachers, students and universities.

From the perspective of management, the absence of positive "school, teaching, learning" spirits is the failure of school supervision system. The main way to promote positive spirits is to strengthen the quality supervision in undergraduate education in details, pay special attention to the key factors affecting teaching and learning spirits, and clarify the ideas, methods and evaluating carriers of teaching and learning spirit construction. A closed-loop system should be formed in teaching units according to the scientific and rational "graded teaching and learning spirits forewarning and disposal system" by combining selfinspection and perambulation, giving graded forewarning signals based on teaching performance, offering relevant improving suggestions, keeping tracking follow-up improvement, and giving feedbacks on the results in time.

As to teachers' influence on positive spirit construction, as long as their development demands are met and their working enthusiasm enhanced, positive teaching spirit will naturally be promoted and teaching quality improved. Thus learning and school spirits will also be rectified. "Teaching Performance Assessing System" aims at guiding teachers' directional development through a set of scientific evaluation data. It collects relevant data on teachers' expertise, development plan, relevant experience and evaluation, relevant research and achievement, and everyday teaching performance. Then, on this basis, it guides teachers to clarify their developing direction and pays special attention to supporting young and mid-aged teachers according to their characteristics for the purpose of fully exploring their expertise, motivating them to hone basic teaching skills, and encouraging them to devote themselves in teaching.

Interaction in class is the direct reflection of undergraduate teaching effect. An information exchanging and feeding back platform should be established on student, teacher and school levels in order to improve classroom discipline, normalize teaching quality supervision, stimulate students' learning interests and selflearning activity, and at last keep up with the current changes in teaching ideas and methods. "Class teaching supporting system", equipped with class interaction, attendance check, evaluation and management functions, is designed to solve the existing problems in learning spirit promotion.

\section{CONCLUSIONS}

\subsection{Governance is an Effective Way to Straighten out Internal Undergraduate Management Mechanism}

Responding to "promote the modernization of state governance system and governance capacity" mentioned in the Third Plenary Session of the 18th CPC Central Party, the modernization of internal undergraduate governance system include "connotative development" and "positive 'school, teaching and learning' spirit promotion". These two parts coordinate with each other in a systematic way and form a comprehensive whole. In terms of connotative development, it is particularly important to focus on talent cultivation, to meet students' developing demand by meeting that of teachers, and to improve talent quality by supporting curriculum construction. Speaking of promoting positive spirits, actual effects can only be achieved by making strict demands on key stakeholders-teachers, students and college and department groups. The internal undergraduate governance system should revolve around teachers, curriculums and students and build various independent closed systems interacting with each other.

\subsection{Scientific and Systematic Governance System Can Achieve Ideal Effects through the Participation of Key Stakeholders and a Successful Mechanism}

The construction of undergraduate governance system should be the new idea in deepening the comprehensive reform on education. As an inevitable choice in current situations, it learns from the governance theory while exploring and concluding the practice of modern university system. As a bridge between theory and practice, it is a word and institutional system as well as an ideology system to help deepen the comprehensive education reform. Starting with teachers' development demands, the governance system aims at allowing multiple subjects to take part in undergraduate affairs, governing by virtue as well as by law, combing management with service, and turning regulations into people's conscious behavior.

\subsection{Governance System Based on University Conditions Achieves Better Effect}

The governance systems adopted by the over 2000 colleges and universities in Chinese mainland apparently cannot be unified, since they each has their own developing direction, characteristics and weaknesses. While adhering to the general governance idea, universities should give enough consideration to their teacher and student structures, talent training objects, discipline structures, histories, reforms and school locations. Instead of blindly copying existing governance patterns, universities having their governance system specially designed are more likely to achieve their goals.

\section{References}

[1] Wang Hongcai. The Inherent Logic of University Governance and Its Selection on Modes [J]. Journal of Higher Education, 2012(9):24-29. 
[2] Huang Jianrong. Public Management: A New Perspective $[\mathrm{M}]$. Beijing: Social Sciences Academic Press (CHINA), 2006.

[3] J Kooiman, M Von Vliet. Governance and Public Management [M].Landon: Sage Press, 1993.

[4] Sun Yongxiang. Company Governance Structure: A Theoretical and Empirical Study $[\mathrm{M}]$. Shanghai: Joint Publishing, 2002.
[5] Zhang Wenjiang. Returning and Exceeding of University Governance [J]. Higher Education Exploration, 2012, (4):8-11.

[6] Complete Works of Marx and Engels [M]. Beijing: People's Publishing House, 2007, Volume 1:82.

[7] Teachers Law of the People's Republic of China, 1993.

[8] Yan Haibo, Lin Rupeng, Zhang Hong. Improve Undergraduate Education Quality: Three "One" Innovative Talent Cultivation Plan [J]. China Higher Education, 2012, (Z3):44-46. 